\title{
Mujer y discurso de género en los arrabales de la lengua y la literatura'
}

\section{Woman and Gender Discourse in the Poor Quarters of Language and Literature}

\author{
GABRIEL NÚÑEZ RUIZ \\ Universidad de Almería
}

España

gnunez@ual.es

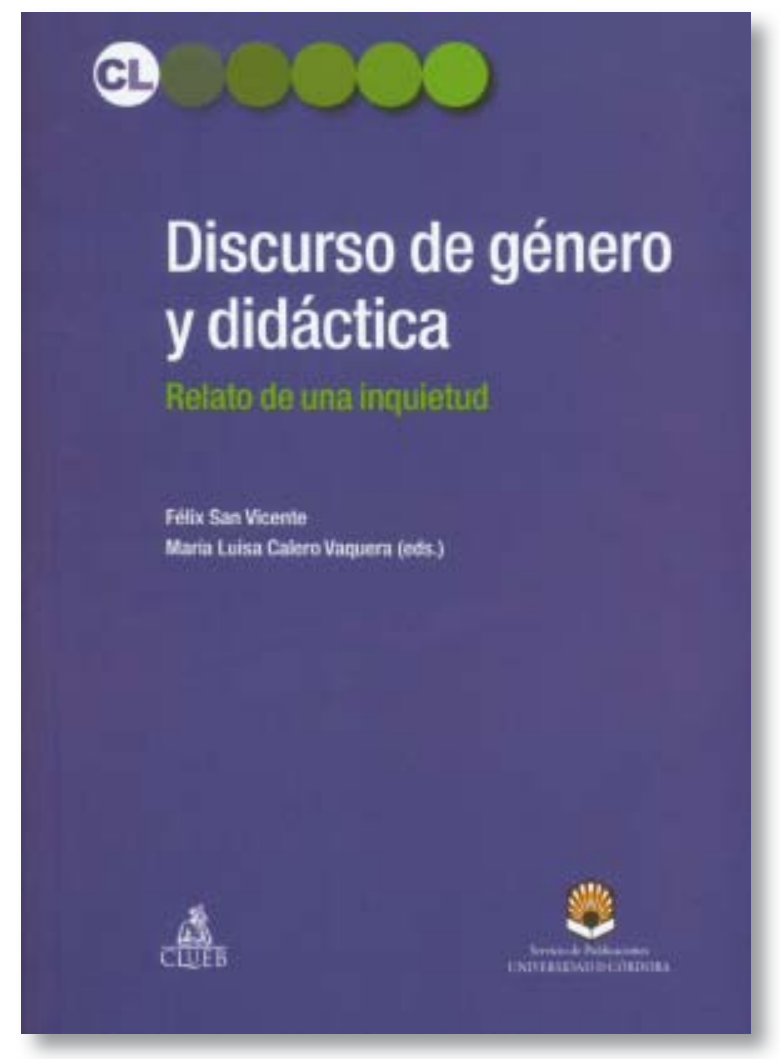

Discurso de género y didáctica

Félix San Vicente y $M^{a}$ Luisa Calero Vaquera (eds.)

Córdoba: CLUEB/Universidad de Córdoba, 2012

\footnotetext{
I Para citar este artículo: Núñez Ruiz, Gabriel (2OI3). Mujer y discurso de género en los arrabales de la lengua y la literatura. Alabe \%. [www.revistaalabe.com] (Recibido 28-I2-2OI2; aceptado 28-I2-2OI2)
} 
Entre las diversas líneas de interés que aborda el texto Discurso de género y didáctica, coordinado por María Luisa Calero y Félix San Vicente, nos resultan especialmente interesantes dos: el modo en que, en distintos periodos y en materiales curriculares lingüísticos y literarios, a los que denominamos arrabales de la lengua y la literatura, se indagan las características relacionadas con la educación de la mujer y con el habla femenina; así como la respuesta que se ofrece a esta pregunta: ¿es sexista en su construcción histórica la lengua española?

Históricamente, y ciñéndonos a la España contemporánea, concretamente, al momento de mediados del XIX en que se instaura el moderno sistema escolar, en los manuales y textos literarios se generaliza el lema de Mesonero: "la mujer, ni idiota ni literata”. Lema que es contestado por los krausistas generalizando la crítica a las mujeres poco instruidas: "son deleznables las mujeres que escriben beso con "v" y creen que Polonia es nombre de mujer”. Igualmente, los hábitos lectores y las lecturas de novelas no tienen por qué ser perjudiciales, y la alabada sencillez femenina será para ellos señal de ignorancia, de vulgaridad.

Para huir de este peligro, Edmundo de Amicis en sus Recuerdos no ve otro camino que el de levantar todas las barreras que ayudan al mantenimiento de esta situación. Ya que Pestalozzi quiso que el proceso educativo se iniciara desde la cuna misma, la madre, convertida así en base del sistema, ha de recibir completa instrucción. Mientras Rousseau, "heraldo de una nueva época", utiliza como única lectura de Emilio no a Aristóteles, sino a Robinson, y el diecinueve le llega a definir como el literato del sexo femenino, Pestalozzi será el experimentador y Froebel el organizador de su educación. Rousseau vio la isla pedagógica como entre nieblas. Pestalozzi se acerca, la mide, la dibuja y hace un plano. Froebel penetra en la isla desconocida, abre en ella los surcos y los siembra. Con estos precedentes es explicable que los institucionistas crearan la escuela de institutrices, con el fin no sólo de desterrar la idea de la mujer incapaz para ejercer cualquier función social, sino que, además, proclama su superioridad para la educación de los párvulos. Y el buscar justificaciones en el pasado para este propósito es ahora normal. En el acto de inauguración de las "Conferencias dominicales para la educación de la mujer” el mismo Fernando de Castro defiende a la mujer virtuosa, casera, hacendosa y con un grado de instrucción tal, que le permita educar a sus hijos dentro del hogar en consonancia con el ideal expresado en La perfecta casada, de Fray Luis de León. La mujer en el diecinueve tenía aún en contra, como Santa Teresa, su condición femenina. Recordemos que Francisco Rico acude a esta visión de La perfecta casada para descubrir las dificultades que tuvo que padecer Santa Teresa en su aventura mística. También la tradición había tejido sobre la mujer una mezcolanza de mentalidad aristocrática y religiosidad medieval a las que resultaba inadmisible toda dedicación demasiado absorbente a las letras. Restricciones y cortapisas que coexisten aún en el siglo XVIII con los aspectos más novedosos de nuestra cultura ilustrada. Moratín, por ejemplo, satiriza en La comedia nueva a aquellas mujeres que descuidan las tareas domésticas para entregarse a la lectura. A la par, Agustina, mujer de Eleuterio Crispín de Andorra, es una marisabidilla que prefiere ayudar a su 
marido en la composición de comedias antes que cuidar de la casa y la familia. De su boca sale la siguiente confesión: "Para las mujeres instruidas es un tormento la fecundidad". Aunque sectores conservadores insistan en la necesidad de no seducir la imaginación de las jóvenes -“Nada pervierte más el sentido moral de las mujeres que la novela”-; el liberalismo decimonónico, distanciándose de los reparos y prohibiciones que pesaban sobre romances, comedias y novelas, prefiere a la santa que, a escondidas de su padre y en connivencia con la madre, recuerda su afición a la lectura en el Libro de la vida; también, al Feijoo que defiende a la mujer; al Jovellanos que achaca a la costumbre su falta de educación, y la habilita para todos los trabajos propios de su sexo; y al Campomanes que pide educación para mujeres e hijas de artesanos. La necesidad de que se operen modificaciones en los sistemas educativos, para que la mujer desempeñe cumplidamente los papeles de madre y esposa y abandone la rutina, frivolidad y descuido imperantes, es abiertamente defendida por el obispo de Orleans, monseñor Dupanloup, en su obra Las mujeres sabias y las mujeres estudiosas. Cristianos y maestras tienen presente que el hogar y la sociedad del diecinueve engendran otras exigencias que no existieron en siglos anteriores. La mujer no debe seguir siendo una sirvienta ni esperar a que el matrimonio la libre de la pobreza por falta de medios para vivir con independencia. Cultivar su inteligencia de modo que sea útil en su profesión y en la educación de sus hijos, es una de las demandas de la sociedad de mediados de siglo. En general, las opiniones de este momento dan por sentado que se han resuelto a favor de la mujer, con la ayuda inestimable de la historia y de los fisiólogos, las preguntas que se venían formulando con anterioridad: ¿Es la mujer inferior al hombre intelectualmente? ¿Es susceptible de mayor instrucción? ¿Es la única misión de la mujer el matrimonio y la maternidad? Para los fisiólogos, el mayor grado de cultura intelectual en el hombre es debido a su mejor educación. La historia es pródiga en ejemplos: Aristea, Teresa de Ávila, Oliva Sabuco, Beatriz Galindo, etc. Y estos argumentos arreciarán, sobre todo, a favor de las mujeres de clase media. Los krausistas traen a sus escritos los tiempos en que mujeres célebres como las hijas del conde de Tendilla se distinguían por su saber, y en que Lucía de Medrano y Francisca de Lebrija regentaban cátedras en Salamanca y Alcalá. Y lo hacen para requerir del gobierno medidas que palien las adversas circunstancias que la mujer halla aún en su siglo. Las élites arremeten contra la instrucción que reciben las mujeres españolas por inadecuada y falta de sentido práctico y moral. Es más, si quiere cumplir el papel de educadora de los hijos, cuyo porvenir tiene en sus manos, y asentar al familia sobre bases racionales que alejen el fantasma de las diferencias que puedan romper la armonía matrimonial, necesita ineludiblemente una educación igual a la del hombre. En suma, debe ser educada par que también comprenda el funcionamiento de la vida pública y para que pueda incorporarse al mundo profesional a través del ejercicio de las diversas profesiones u oficios.

En el artículo de María Luisa Calero se completa esta visión señalando el progreso social que han experimentado las mujeres españolas en el último siglo.

Otro de los centros de interés de este volumen lo constituyen los estudios que afrontan el análisis ideológico de gramáticas y diccionarios, dos de los instrumentos con 
mayor tradición en los sistemas educativos europeos. En estos materiales, al igual que sucede con las Historias de la literatura, se transmite el credo nacionalista y una visión de la mujer en la que se minusvalora la faceta pública de la misma. Tales materiales didácticos en tanto que discursos con los que aprendemos las lenguas (gramáticas, diccionarios, ortografías), manifiestan estrategias semánticas que contribuyen a la perpetuación de ciertos estereotipos sociales, como nos demuestra Susana Rodríguez Barcia, apoyándose en citas de profesores como López Valero o Cortés Rodríguez, quienes vienen incidiendo en el carácter inconsciente, y por ello más efectivo, que ofrece el sexismo en el lenguaje. Así, por ejemplo, se aprecia cómo los ejemplos inventados por los redactores de las primeras gramáticas académicas se han trasladado a lo largo del tiempo al margen de los regímenes políticos o las ideologías dominantes en determinados periodos de la historia de España. Concretamente, en este ensayo se describen algunos de los elementos de la cultura escrita que en la enseñanza de la lengua han contribuido a la aceptación de estereotipos sociales que se han repetido en los distintos niveles del sistema educativo. El peso de la herencia cultural y la tradición han prevalecido sobre los contextos políticos y las ideologías de las diversas etapas de nuestra historia.

En el caso concreto de los diálogos, las mujeres tienen un papel secundario o reflejan las ideas que sobre las mismas se recogen en el imaginario masculino de la época. Así, se aprecia también en algunos diccionarios, tal como sucede en el Tesoro de Cobarrubias. Aquí se nos muestra la vida social de la España de los Austrias, en la que la mujer es un personaje secundario a la par que un ser con múltiples defectos.

En fin, hemos querido perfilar un breve relato relacionado con este excelente volumen, que contiene también algunos otros aspectos que aquí no se abordan; sin embargo, creemos que los aquí tratados harán ver al lector el rigor, la extensión histórica y los múltiples y actuales aspectos que, en relación con la mujer y la enseñanza de la lengua se tratan en él. 